\title{
EVOLUCIÓN DE UN CENTRO ASISTENCIA MEDIEVAL LEONÉS: EL HOSPITAL DE SAN MARCELO (1084-1531)
}

\author{
MonSERRAT PRADA VilLALOBOS
}

\section{Resumen}

El hospital de San Marcelo estaba emplazado en una posición estratégica dentro de la ciudad de León. Pertenecía a la abadía del mismo nombre, y fue la primera alberguería de la que se tiene constancia en León, perdurando durante toda la Edad Media hasta 1531, año en el que se anexionó al hospital de San Antonio Abad. Era uno de los hospitales más destacados de la ciudad.

\section{Palabras clave}

Abadía, abad, hospital, obispo, cabildo catedralicio, provisor, racioneros, proveedor y hospitalero.

\begin{abstract}
San Marcelo's Hospital was placed in a strategic position in the city of León. It belonged to the abbey of the same name, and it was the first Lodging in León, where it staid along the Middle Ages until 1531, when it was annexed to San Antonio Abad's Hospital. It was one of the most remarkable Hospitals in the city.
\end{abstract}

\section{Key words}

Abbey, abbot, hospital, bishop, cathedral's chapter, provisor, prebendary, dealer and hospitalero

\section{Introducción}

Su denominación se la debe a un centurión, nacido en la segunda mitad del siglo III, que perteneció a la primera cohorte de los hastados de la Legio VII, y dió su apelativo a la ciudad ${ }^{1}$.

Será el primer hospital del que tenemos constancia en la ciudad de León, trasladado en dos ocasiones de emplazamiento, en sus comien-

\footnotetext{
${ }^{1}$ Al celebrarse con fiestas públicas el cumpleaños del emperador Maximino, el centurión se negó a quemar incienso ante la efigie del César y por ello fue hecho prisionero y conducido a Tánger, donde fue degollado el veintinueve de octubre del año 298 D.C., siendo sepultado en el lugar del martirio.

Su cuerpo permanecerá en Tanger hasta el año 1471 cuando Alonso, rey de Portugal, conquistó esa ciudad, ese mismo año don Gómez Díaz de Isla, abad de San Marcelo, lo llevó de allí, primero a Jerez y después a Sevilla, trayéndosele a León en 1493, donde es sepultado en el templo del mismo nombre el veintinueve de marzo, en presencia del rey Católico, al que acompañaban muchos caballeros, entre los que se encontraban el almirante de Castilla, el marqués de Astorga, el conde de Luna, don Bernardino, hijo del condestable, Rodrigo de Ulloa, contador mayor, Fernando de Acuña, virrey de Galicia.

Más información sobre el santo se obtiene en la obra de B. DE GAIFFIER "A propos de S Marcel Le Centurion", en Archivos Leoneses, León, 1969, pp. 13-23.
} 
zos, en 1084, se situó muy cerca de la iglesia de Santa María, hasta que en 1096, se ubicó definitivamente en la que sería su instalación durante el resto de la Edad Media, al oeste de la Puerta Cauriense, en la colación de San Marcelo que se constituyó a principios del siglo XIII como la parte más reciente del Burgo Nuevo.

Su fundación, bajo el reinado de Alfonso VI, responde al impulso de un nuevo espíritu caritativo, en el que las hospederías monásticas, comienzan a dar paso, a la fundación de otro tipo de centros asistenciales en las ciudades en las que obispos y cofradías, tanto gremiales como religiosas, jugarán un papel destacado.

Junto con el hospital de don Gómez, serán los dos centros hospitalarios pertenecientes al cabildo catedralicio más importantes de la urbe en los siglos bajomedievales, engrosando en su patrimonio un amplio número de propiedades que, tras su anexión en 1531 al hospital de San Antonio, pasarán a depender de este último.

\section{1- Patrimonio.}

La primera noticia que tenemos sobre este hospital, data del año 1084, fecha en la que el obispo Pelayo lo fundó con el objetivo de practicar la atención a los pobres, aunque sería catorce años más tarde cuando el sucesor de Pelayo, el obispo don Pedro, lo traslada de su ubicación originaria a la que luego ocuparía hasta su desaparición ${ }^{2}$, y para su mantenimiento dona bienes situados en Trobajo, Marialba, San Andrés de Rabanedo, Santa Olaja de la Ribera, Vega de San Adrián, Fojedo y Montefrío (una villa en Palanquinos, la tercera parte de Cavatellos, en el Valderaduey, y el territorio en Salnellas, Santa María Abarca, y la iglesia de San Andrés en el valle Carregoso. Además concede el diezmo del pan y del vino, tanto de las décimas, como de las colectas, y el diezmo de todas las heredades que les entrega, un excusado por cada una de estas villas, el diezmo de la sal de Lampreana y de las oferciones que hicieron a Santa María ${ }^{3}$.

\footnotetext{
${ }^{2}$ Está situado al oeste de la ciudad entre la iglesia de San Marcelo y la casa del ayuntamiento. La fachada queda enfrente a la plaza del mismo nombre. La ubicación del hospital en 1096 se situará en el lugar donde habían estado emplazadas las iglesias de San Marcelo, Santiago y San Adrián, construidas en la parte exterior de la antigua muralla, junto a la Puerta Cauriense, por debajo del palacio real, y que había ido quedando destruidas con el tiempo, edificándose en su lugar una iglesia y un hospital en honor de San Marcelo.

${ }^{3}$ RUIZ ASENCIO, J.M., Colección Documental del Archivo de la Catedral de León. (775-1239). IV (10321109), León, 1990, documento $\mathrm{n}^{\circ} 1291$.
} 
Como ya hemos indicado doce años antes, en 1084, el obispo Pelayo, antecesor en el cargo de la sede leonesa de Pedro, instituye un hospital para atender a los peregrinos y a los pobres que allí acudiesen, dicha domus hospitalis, encargada de la labor de hospitalidad estaría situada junto a la iglesia leonesa de Santa María, es decir en el centro de la ciudad.

El obispo Pelayo la dotará con la villa de Palanquinos, tres viñas en Castrello (Castrillo de la Ribera), cuatro en Aupelaire (Golpejar), la décima del vino de la viña que el obispo plantó en Castrello (Castrillo de la Ribera), en Villa Havive, una viña y un huerto, la tercera parte de la viña y el huerto que mandó plantar en Paradilla, sendas viñas en Montefrío (cerca de Navatejera) y en Santa Marta, el diezmo de la viña que plantó el conde Diego Ansúrez, en Matallana, la tercera parte del diezmo de las viñas plantadas por el obispo en Villa Veiga, cerca de Castro Havoce, en Villa Carlón, capillas y villa de Bovata (Boada de Campos), el diezmo de la sal que poseía dicho obispo en Lampreana, y las porciones de diezmo que Pelayo tenía en Villa Reiligos (Reliegos) y Auteiros Regis (Oteros del Rey), y las tercias íntegras que solían dar a la sede Melgar y Villa Nava.

En 1102 a sus donaciones iniciales Pedro añadirá la heredad que había comprado en Paradilla a Juan Domínguez y a su mujer, María Álvarez, por cuatrocientos cuarenta sueldos y la viña que adquirió a Seguino en el lugar de San Pedro de los Huertos ${ }^{5}$. Alfonso VI, monarca reinante en esas fechas, agrega a los anteriores legados la heredad de Lorenzana.

Lo que a simple vista parece ser la creación de dos hospitales independientes entre sí, carentes de conexión, en realidad responde a la doble fundación de un mismo hospital por dos obispos diferentes, que en sólo catorce años experimentará un cambio en su localización. El primer historiador que reflejó esta hipótesis fue Gregorio del Ser Quijano ${ }^{6}$, que defiende su tesis afirmando que muchos de los bienes de los dos centros hospitalarios serán coincidentes, lo que parece más indicativo de que los dos albergues responden a una misma realidad, más que a que en un bre-

\footnotetext{
${ }^{4}$ RUIZ ASENCIO, J.M., Colección Documental del Archivo de la Catedral de León (775-1230). IV (10321109), León, 1990, documento $\mathrm{n}^{\circ} 1236$.

${ }^{5}$ RUIZ ASENCIO, J.M., Colección Documental del Archivo de la Catedral de León (775-1230). IV (10321109), León, 1990, documento $\mathrm{n}^{\circ} 1312$.

${ }^{6}$ DEL SER QUIJANO, G., "Algunos aspectos de la caridad asistencial altomedieval. Los primeros hospitales de la ciudad de León”, en Studia Historica, vol. VIII, n 12, 1985, pp.157-179.
} 
ve lapso de tiempo se concediese las mismas propiedades a dos centros diferentes, los cuales a su vez dependerían de la misma institución, que en este caso era la iglesia leonesa.

Del Ser defiende el traslado argumentando razones de tipo urbanístico y de comodidad ${ }^{7}$, para mayor holgura de los peregrinos que llegaban por el Camino Francés a León, porque el hospital de San Marcelo al estar situado en una zona menos céntrica, fuera de la muralla, pasada la Puerta Cauriense, dispondría de espacio para futuras ampliaciones, teoría con la que no estamos de acuerdo, pues al menos hasta el siglo XIII existió al lado de la catedral un hospital conocido con el nombre de San Juan $^{8}$.

Este hospital se enmarca dentro del abundante número de fundaciones, que bien directa, o bien indirectamente, pero bajo su auspicio y beneplácito, se crean durante el reinado de Alfonso VI, no sólo dentro del marco urbano leonés, sino también en otras villas del reino, entre las que la más significativa será la de Sahagún.

La iglesia de San Marcelo tuvo, al menos un huerto en el Santo Sepulcro, mencionado en 1223, y un horno cerca de dicha iglesia ${ }^{9}$. En el corral de San Marcelo la alberguería contaba con quince casas que son visitadas en 1461, encontrándolas los canónigos en buen estado, aunque necesitaban retejar, a lo que había que añadir otras casas dispersas por la ciudad, así como una serie de suelos y huertos dentro de la ciudad. Fuera del casco urbano sabemos que en estos momentos tenían también propiedades en Castrillo y en Roales ${ }^{10}$.

\footnotetext{
${ }^{7}$. Afirma "Parece más lógico pensar que, al efectuarse la construcción y dotación subsiguiente del hospital de San Marcelo, se procedió al desmantelamiento del anterior, situado frente a la iglesia catedral, aunque no lo diga explícitamente en la documentación conservada". (DEL SER QUIJANO, G., Los Primeros hospitales, p.162).

${ }^{8}$ Encontramos referencias a este centro asistencial en 1243, cuando el maestre Monio, chantre, le dona "domos quas ipsi michi concesserant quos ego teneban pro treginta moropetinos pro pauperibus vestiendis" (RUIZ ASENCIO; J.M., Colección Documental del Archivo de la Catedral de León. VIII (1230-1269), León, 1993, documento $\mathrm{n}^{\circ}$ 2049; y en 1270 aperece la última referencia que tenemos sobre él en el testamento de don Yuanes, en el que entre otras mandas testamentarias entrega a Pero Rodríguez, capellán de Sant Yuanes de Santa María de Regla, un maravedí. (RUIZ ASENCIO, J.M., Y MARTÍN FUERTES, J.A., Colección Documental del Archivo de la Catedral de León, IX (1269-1300), León, 1994, documento $\left.\mathrm{n}^{\circ} 2295\right)$.

${ }^{9}$ ESTEPA DÍEZ, C., Estructura social de la ciudad de León. Siglos XI-XIII, León, 1977, p. 347.

${ }^{10}$ En Castrillo tenían varias viñas, una tiene cuatro cuartas y la otra se encuentra llena de zarzas y espinos y "rala de cepas".

En Roales poseen varias casas principales de cuyas estancias señalan:

- La cocina está mal reparada.

- Hay un lagar "con su lagarera e pilon e viga e piedra". Todos en buenas condiciones, pero se debe retejar porque tiene goteras y poner cerraduras.

- Encuentran una "desgravedera" de tintas, dos tinas viejas y una cuba vieja descompuesta.

- Hallan un establo que está en el corral mal reparado.
} 
Este hospital aparecerá vinculado durante toda la Edad Media a la iglesia- catedral de León, y su importancia debió de ser considerable, a tenor, no sólo del importante número de propiedades, villas y diezmos, y otras posesiones, que estaban bajo su dependencia directa, sino también, por el número de personas encargadas del mantenimiento del centro, que debían ser en torno a veinte, hasta 1305, año en que se reducen a ocho los clérigos que estaban asignados al hospital, a lo que hay que añadir que en los portales del hospital se reunirá, durante toda la Edad Media, el concejo de León, para tomar sus decisiones ${ }^{11}$.

Al igual que nos sucedió al analizar el hospital de San Lázaro y nos ocurrirá con muchos otros, observamos que muchas de las donaciones de tierras corresponden a viñedos, lo cual podría responder a que la práctica de la caridad en la Edad Media, además de la cesión de fuego y sal, consistía en proporcionar vino o preparados, cuyo ingrediente fundamental era la uva, para restablecer a los pobres o peregrinos, que en la mayor parte de los casos llegaban a estos centros desfallecidos.

El hospital se beneficiaba con el cobro de parte del portazgo y zavazogazgo de las ciudades de León y Astorga, que pertenecían a la monarquía y fueron cedidas por la reina Urraca en el año $1113^{12}$, lo que le llevará en ocasiones al enfrentamiento con el concejo de la ciudad, como ocurrirá en 1308 cuando Fernando IV manda al concejo y a los jueces de la ciudad de León que dejen al hospital de San Marcelo cobrar portazgo por las mercancías que entran en dicha ciudad ${ }^{13}$.

También serán frecuentes en las mandas testamentarias encontrarnos con la donación de lechos y enseres relacionados con ellos, los

\footnotetext{
- Hallan en el corral una pila de piedra y todas las paredes del corral "sin barda".

- Unas casas que tiene Juan de Aragón, que están en buenas condiciones y pagan de fuero cuatro maravedís y un par de gallinas.

- Una casa que tiene Alonso del Valle, que está en buen estado y paga por ella seis maravedís y un par de gallinas.

Además de las casas tenían en Roales otras propiedades:

- Unos suelos que tiene Fernando Sánchez y un huerto de fuero de seis maravedís y un par de gallinas.

- Unos suelos que tiene Diego de Carvajal, sujetos a un fuero de cuatro maravedís y dos gallinas.

- Unos corrales que tiene Juan Pellitero, sometidos a un fuero de tres maravedís y una gallina.

- Un huerto que tiene Rodrigo majadero, sujeto a un fuero de un maravedís y una gallina.

- Un ferreñal que tiene Esteban y hace ocho celemines de sembradura, sujeto a un fuero de seis maravedís y un par de gallinas.

- Otro ferreñal que tiene Rodrigo Majadero de cuatro heminas de sembradura.

- Once tierras, que entre todas tienen cuatro heminas de sembradura, estando algunas sin arrendar.

${ }^{11}$ ESTEPA, La ciudad de León, p.485.

${ }^{12}$ ESTEPA, La ciudad de León, p.269.

${ }^{13}$ Archivo de la Catedral de León, n969, y GARCÍA VILLADA, Catálogo de los Códices y Documentos de la Catedral de León, Madrid, 1919, p.132.
} 
más frecuentes serán mantas, sábanas, almohadas, colchones, etc, además de dinero y ganado, casi exclusivamente vacuno, lo cual nos viene a señalar que el hospital complementaba la agricultura con la práctica ganadera, pues probablemente la carne sirviese para alimentar a los pobres ${ }^{14}$.

En 1302 el obispo y el cabildo decidieron construir una nueva iglesia y hospital de San Marcelo, "el uno por su escasa capacidad y la otra por su estado ruinoso ${ }^{15,}$.

Dentro de la política de laiquización que había comenzado en la Baja Edad Media y se acentúa en época moderna, y también continuando con el proceso de concentración hospitalaria iniciado bajo el reinado de los Reyes Católicos, en 1578, el obispo y el cabildo de la catedral de León, ceden los hospitales de San Antón y de don Gómez, anexos a la catedral, al ayuntamiento de la ciudad, y para los propios de ésta dos prados, sitos entre los monasterios de San Francisco y de San Claudio, y otro prado en la orilla del río de San Marcos, a cambio de la licencia para mantener cerrados unos prados nuevos que debían abrirse en otoño para pastizal común de los ganados ${ }^{16}$.

En 1758 agregaron las rentas de la malatería de la ciudad a las de este hospital, vendiéndose algunas de sus fincas en tiempos de Carlos IV.

\section{2- Ejercicio de la labor asistencial.}

La gestión del hospital estaba en manos de los abades de "San Marcelo", encargados también de regir la iglesia de dicho nombre, y cuyos nombres podemos rastrear a lo largo de toda la Edad Media, gracias a la documentación de la catedral leonesa, y sobre todo, a las actas capitulares.

Ya desde el siglo XII estaba secularizada la canonjía de San Marcelo, sustituyéndose a los canónigos regulares que allí vivieron por clérigos seculares. El cuidado de la iglesia y su hospital queda a cargo del

\footnotetext{
${ }^{14}$ Entre los numerosos ejemplos que podemos citar estaría, por ejemplo, la donación de Pedro Iohannis, arcediano de León, que entrega al hospital de San Marcelo "omnes preseas quas habeo et ropam et lectos, et unam vinam quam comparavi in Roales, et illam hereditatem quam comoparavi in Toldanos con suys vineys, et illas conpraciones quas ibi feci et vienas quas comparavi in Palanquinos, et casas que habeo in majorica, et vacas quas comparavique sunt cum ganato Sancti Marceli.". (Colección Documental de la Catedral de León, $\left.\mathrm{n}^{\circ} 2072\right)$.

${ }^{15}$ VÁZQUEZ DE PARGA, L., LACARRA, J.M., URÍA RÍU, J., Las peregrinaciones a Santiago de Compostela, Madrid, 1948, p.256.

${ }_{16}$ ÁLVAREZ ÁlVAREZ, C., Y MARTÍN FUERTES, J.A., Archivo Histórico Municipal de León. Catálogo de los documentos, León, 1982, documento $\mathrm{n}^{\circ} 813$.
} 
cabildo quien nombra un canónigo de la catedral que recibe el título de provisor de San Marcelo, a cuyas órdenes servían los clérigos.

Será en 1243 cuando el papa Alejandro IV expide una bula autorizando al cabildo para nombrar rector, concediéndole también la administración del establecimiento, recayendo dicho oficio en uno de sus miembros, teniendo además el cabildo facultad para destituir al rector. Esta bula será confirmada por Inocencio IV.

En el siglo XIV el obispo y el cabildo establecen que la iglesia y el hospital dejen de ser beneficio perpetuo y pasen a ser administración temporal; el once de enero de 1306 el obispo don Gonzalo Osorio y el cabildo determinan que la iglesia, con la dirección y gobierno del hospital, sean en adelante dignidad de la catedral recibiendo el título de abadía. $\mathrm{Su}$ provisión corresponde al obispo con consentimiento del cabildo, y debe recaer en un canónigo de la catedral. El abad es el administrador del hospital y ejerce la máxima autoridad en él, pero siempre dependiendo de la autoridad episcopal ${ }^{17}$.

Para ser abad, tanto de San Marcelo como de San Guillermo, se debía ser canónigo del cabildo leonés, pudiendo acumular beneficios y tener asiento a continuación de las antiguas dignidades, en las reuniones capitulares.

Conocemos el nombre de la mayor parte de los abades que tuvo San Marcelo a lo largo de la Edad Media, y así, sabemos que el veinticinco de octubre de 1316, es abad Fernando Martínez, ya que firma como testigo en una escritura, y que el veintitrés de septiembre de 1419, obtuvo la abadía don Juan de Bondreville, colector papal y canónigo (en lo que se puede considerar como una de las muchas injerencias papales en los nombramientos episcopales de los distintos cargos capitulares a lo largo de toda la Edad Media), tras la muerte de su anterior abad, don Gonzalo de Villamañán, pagando por la concesión de la dignidad una capa de seda de damasco blanco.

Don Juan de Bondreville tendrá una participación escasa en el cabildo, pues como colector general del papa en la provincia de Santiago, dispondrá de una bula papal que le dispensa de asistir al cabildo y demás actos del coro durante un período de cinco años, en los cuales puede disfrutar de los frutos de todos sus beneficios.

\footnotetext{
${ }^{17}$ NICOLÁS CRISPÍN, Mª I., BAUTISTA BAUTISTA, M., GARCÍA GARCÍA, M ${ }^{\mathrm{a}}$. T., La Organización del Cabildo Catedralicio Leonés a Comienzos del S. XV (1419-1426), León, 1990, p.171.
} 
A finales de la Edad Media el cargo de abad era ostentado por personas que lo habían recibido en permuta con otro puesto, como ocurrirá en el año 1468, cuando Gómez Díaz de Isla, arcediano de Carballeda, dignidad de la iglesia de Astorga, toma posesión de la abadía de San Marcelo por intercambio (no se especifica que fue lo que se canjeó para la obtención de dicho oficio), aunque continua manteniendo su cargo en el arcedianato de Carballeda.

Los mandatos de los abades de la segunda mitad del siglo XV se caracterizarán, no sólo, por luchas intestinas por el control de una ocupación que implicaba enormes beneficios, sino también, por la corrupción, la desatención del hospital, y las intervenciones regias en los nombramientos y destituciones de los abades, todo lo cual repercutió negativamente en el buen funcionamiento interno del centro ${ }^{18}$.

Así, veremos como en 1482 Antonio de Villagómez, tras dejar la abadía es conminado por el cabildo a que "pague a los racioneros de San Marçiel todo el pan y el vino que les debe del dicho tiempo que fue abbad fasta el dia de Sant Lucas primero veniente so pena de descuento al señor chantre como su fiador e que el dicho señor chantre torne al hospital çierta ropa que tomo o mando tomar fasta el dicho termino e otrosy mandaron los dichos señores al señor don Francisco de Villamysar abbad de Sant Marçiel que pague a los dichos racioneros todo lo que debe a los dichos racioneros del año pasado de ochenta años sopena de descuento ${ }^{19}$,"

La disciplina interna tampoco debía estar muy consolidada en estos momentos, encontrándonos con varios casos de insubordinación de racioneros contra sus abades, como ocurrirá en 1482 cuando el abad Francisco de Villamizar denuncia ante el cabildo al racionero Francisco de Moros "por algunas palabras injuriosas que dixo, que el dicho Francisco a el avya dicho ${ }^{20 "}$.

Además, ya sea porque cobraban sueldos muy reducidos o por otros motivos, los racioneros, en ocasiones no desempeñaban bien sus funciones, y así, en junio de 1470, los racioneros de San Marcelo, junto con los bachilleres de los doce, se negaron a "velar las velas que les fue-

\footnotetext{
${ }^{18}$ En junio de 1488 el doctor de Villada es restituído en su puesto como abad de San Marcelo, del cual "avya sydo despojado por mandamyento delos Reyes Catolicos". (Actas Capitulares, caja $\mathrm{n}^{\circ} 388$, documento $\mathrm{n}^{\circ}$ 9826).

${ }^{19}$ Actas Capitulares, caja no 388 , documento ${ }^{\circ} 9823$.

${ }^{20}$ Actas Capitulares, caja $\mathrm{n}^{\circ} 388$, documento $\mathrm{n}^{\circ} 9823$.
} 
ren echadas ${ }^{21}$ ", y en agosto de 1478 el cabildo manda que no se de pan ni vino a los racioneros de San Marcelo que no asistan a la iglesia "sin que tengan y muestren cartas 22 ".

Ya en 1466 el cabildo se había visto obligado a "dar orden a los rracioneros de Sant Marciel asi a los quatro dellos que sirven en el coro como los otros quatro que sirven en Sant Marçiel non sirven como deven por la pena ser pequena de dos maravedis cada dia ellos avido sobre todo su deliberacion tasaron cada rracion pan e vino e dinero a cada uno que ha de aver en cada año veynte cargas de pan meytad trigo e meytad centeno por la medida vieja e un carral de vino enesta manera el par de las cargas de trigo e centeno por la dicha medida ${ }^{23}$ ".

A todo ello hay que unir las deudas contraidas por las personas que arrendaban las propiedades de la abadía y del hospital, como ocurrirá, por ejemplo, con el prioste Juan González de Zamora, al que se le pide, en 1485, que diese todos los maravedís que debía a la abadía y al hospital de San Marcelo "para provisión de los pobres del dicho espi$\operatorname{tal}^{24,}$.

En 1475 se nombran por receptores de las rentas y bienes pertenecientes a la abadía y hospital al tesorero Fernand Vaca, y a Juan Martínez de la Talla, al bachiller Alvar de Villafañe, canónigos los cuales "dieron poder complido para que resçiba las dichas rentas e paguen todos los encargos dela dicha abadia e hospital e los reparos del dicho hospital e posesiones dela dicha abadia e lo rescata lo tenga en seda e secreto para lo que mandaren los dichos señores provisor e cabillo ${ }^{25}$ ".

La situación en la que se encontraba el hospital debía ser bastante grave pues ese mismo año el obispo de León, Íñigo Manrique, así como otros canónigos y dignidades se reunieron porque "el abbad de Sant Marçiel e hospital de Santo Anton avia de ser regido e admynistrado por el dicho obispo e cabillo segund las constituciones e hordenanças que sobre ello fablan e ellos avian de faser conplirlos encargos al abbad que por el tiempo es dela dicha abbadia e que agora sabian e saben que el dicho hospital esta mal reparado y el pan e ropa e otras provysiones que se han de dar a los pobres no se cumple ny menos los racioneros son pagados y

\footnotetext{
${ }^{21}$ Actas Capitulares, caja $\mathrm{n}^{\circ} 386$, documento $\mathrm{n}^{\circ} 9816$.

${ }^{22}$ Actas Capitulares, caja $\mathrm{n}^{\circ} 386$, documento $\mathrm{n}^{\circ} 9820$.

${ }^{23}$ Actas Capitulares, caja ${ }^{\circ} 385$, documento no 9813.

${ }^{24}$ Actas Capitulares, caja ${ }^{\circ} 388$, documento ${ }^{\circ} 9820$.

${ }^{25}$ Actas Capitulares, caja no 386 , documento no 9818.
} 
que el dicho hospital se quiere caher sy no se repara por ende que ellos deputavan para remediar e veer en todo sus dicho al señor maestrescuela e Iohan Martines de la Talla, García de Mansilla, Juan de Villalpando e Pedro de Remondo junto con este dicho señor obispo e ytem el dicho señor obispo junto con los dichos señores deputaron por reçeptores de las rentas e frutos dela dicha abbadia a los dichos Garcia de Mansilla e Pedro de Remondo a los quales dieron todo su poder complido segund que mejor que lo podian e devian de dar para reçebir recabdar todos los dichos frutos renta de la dicha abbadia e complir dellos todos los cargos e reficiones aquel el abbad de Sant Marçiel es obligado segund desponen las constituçiones que sobre este caso fablavan e lo mandavan e dieronles poder para dar cartas de pago e toman cuenta en forca e el dicho señor obispo junto con los dichos señores quedaron de sacar a pas e a salvo a los dichos Garcia de Mansilla e Pedro de Remondo e luego el dicho Pedro de Remondo que presente estava dixo que el no podia entender ny conplir este cargo que le ansy davan por quanto era ocupado de muchos negoçios e el dicho señor obispo le mando sopena de excomonyon que lo açeptase e luego el dicho Pedro de Remondo respondio que pues el dicho señor obispo se lo mandava sopena de excomonyon que no podia menos faser que pedia e pedio a my el dicho notario que se lo dise ansy por testimonio signado e que lo reçebia ambos los dichos Garcia de Mansilla e Pedro de Remondo con este cargo e condiçion que fueron obligados a dar cuenta e mas de lo que reçebiesen de la dicha abbadia ${ }^{26,}$.

A García de Mansilla, canónigo, le encontramos encargándose de la administración del hospital de don Gómez, por lo que su gestión debía de ser buena, al encomendarle el cabildo que se encargase también de la gestión del hospital de San Marcelo.

Será abad de San Marcelo hasta 1478, año en que estaba en pleitos con don Antonio de Villagómez por dicha abadía, la disputa es ganada momentáneamente por este último, pues en 1479 figurará como abad en la documentación hasta que el siete de agosto de ese año es reintegrado en su cargo Gómez Díaz de Isla, que durará poco en el cargo pues un año después (el once de septiembre de 1480) encontramos como abad de San Marcelo a Francisco de Villamizar, desconociéndose cuáles fueron las causas que llevaron a este cambio repentino de abad, cuando parecía que el enfrentamiento entre sus anteriores abades había quedado definitivamente resuelto.

\footnotetext{
${ }^{26}$ Actas Capitulares, caja n ${ }^{\circ} 388$, documento $n^{\circ} 9825$.
} 
Francisco de Villamizar continua en este puesto en 1481, pero en estos momentos estaba enfermo, ya que el veintiséis de septiembre se le concede "que se pueda absentar desta çibdad para todo el mes de octubre, y que no quiebre la residencia para se curar e convalesçer ${ }^{27, "}$.

El veintiséis de agosto de 1486 el doctor Villada, capellán real, familiar del cardenal vicecanciller tiene por provisión la administración de la abadía y hospital de San Marcelo "donde dize que se acogen muchos pobres asy sanos como enfermos a lo qual e para reparo del derecho ospital para ocho clérigos el obispado de las rentas de la abadía ${ }^{28,}$.

En noviembre de ese año, el gobierno de la abadía parece que había mejorado, pues veremos como se da un "ultimatum" al doctor Pedro de Villada para que pague las cantidades adeudadas a los racioneros so pena de descuento ${ }^{29}$, y, un año más tarde, en 1487, el cabildo nombrará como visitadores del hospital a Luis González de Oviedo, maestrescuela y a Fernanado de Salazar, beneficiado, para que "viesen los quales pobres avian menester y todo lo que fuese menester para ellos lo diese el sochantre Alvaro de Castrillo de los descuentos de los racioneros de Sant Marçiel de que es contador e luego llevaron treynta reales por my çedu$1 a^{30}$.

En 1490 continua el doctor Pedro de Villada como abad de San Marcelo, del que sabemos que en esa fecha vivía en una casa en la calle de Ferrería de la Cruz. A este proceso de decadencia generalizada a finales del siglo XV se unirán otros indicios, y así, sabemos que en 1474 se abre una pesquisa para establecer las causas de la desaparición de un cáliz, perteneciente al hospital, que el maestrescuela y Rodrigo Vaca dieron a Juan de Ordás ${ }^{31}$.

Ese mismo año los miembros del cabildo otorgaron a Juan Martínez de la Talla y a Pedro de Remondo la capacidad para recibir los frutos de la abadía de San Marcelo y "dieronles poder ha todo ello e las que bastaren ha todos los encargos a quel abbad es obligado e convyene a saber pagar los racioneros e para el hospital e para los pobres e para el sacristan e todos los otros encargos los quales el abbad non comple se-

\footnotetext{
${ }^{27}$ RODRÍGUEZ, R., “Extracto de Actas Capitulares”, en Archivos Leoneses, 1962, n 32, p. 312.

${ }^{28}$ R..G.S., fol. 69.

${ }^{29}$ Actas Capitulares, caja $\mathrm{n}^{\circ} 388$, documento $\mathrm{n}^{\circ} 9825$.

${ }^{30}$ Actas Capitulares, caja $\mathrm{n}^{\mathrm{o}} 388$, documento $\mathrm{n}^{\mathrm{o}} 9825$.

${ }^{31}$ Actas Capitulares, caja no 386 , documento $\mathrm{n}^{\circ} 9816$.
} 
gund es obligado por las constituciones dela iglesia e otorgaron cartas firmes 32 ".

Un año después esta situación caótica no se había solucionado y, el 5 de julio de 1475, los señores del cabildo nombraron por receptores de las rentas y bienes pertenecientes a la abadía y hospital de San Marcelo al tesorero Fernando de Vaca, a Juan Martínez de la Talla, y al bachiller Alvar de Villafañe, canónigos ${ }^{33}$.

En estos momentos bajomedievales el oficio de abad de San Marcelo era visto como un beneficio al que todos los eclesiásticos deseaban acceder debido a las importantes rentas que llevaba implícitas, por lo que las labores asistenciales y de atención al hospital que correspondían al cargo quedaban relegadas para los sucesivos abades a un segundo plano, con las consecuencias negativas que ello implicaba para el buen funcionamiento del hospital.

Además del abad también se disponía de racioneros, a los que ya hemos mencionado anteriormente, que eran elegidos por el propio abad, a quien debían obediencia, no pudiendo desempeñar a la vez estos cargos y los de bachilleres del coro.

Los racioneros tenían sus antecesores en los clérigos que servían en la iglesia de San Marcelo y prestaban sus servicios en el hospital del mismo nombre, hasta que en 1306, como ya indicamos, don Gonzalo eleva esta iglesia y hospital a dignidad de la catedral con el título de abadía, siendo entonces los clérigos sustituidos por los racioneros. Desde entonces los racioneros de San Marcelo tienen oficio como tales en la catedral y, al mismo tiempo, ejercen las labores que tenían encomendadas en San Marcelo. Esta acumulación de oficios dio lugar a que no se desempeñasen convenientemente ninguno de ellos, por lo que se ordena que cuatro se ocupen del servicio de la catedral, y los otros cuatro del de San Marcelo. Estos racioneros eran clérigos, lo que se desconoce es sí también debían ser sacerdotes, aunque no era condición indispensable que estuvieran ordenados presbíteros.

Entre 1419 y 1426 sólo conocemos el nombre de uno de estos racioneros: Alfonso Cerón, familiar del abad Don Juan de Bondreville.

\footnotetext{
${ }^{32}$ Actas Capitulares, caja $\mathrm{n}^{\circ} 386$, documento $\mathrm{n}^{\circ} 9817$.

${ }^{33}$ A los cuales se "da poder complido para que resçiba las dichas rentas e paguen todos los encargos dela dicha abbadia e hospital e los reparos del dicho hospital e posesiones dela dicha abadia e lo rescata lo tenga en seda e secreto para lo que mandaren lo dichos señores provysor e cabillo", (Actas Capitulares, caja n ${ }^{\circ} 386$, documento $\mathrm{n}^{\mathrm{o}}$ 9818).
} 
Se situaban a continuación de los bachilleres del coro, pero su asistencia y el cumplimiento de sus obligaciones debió de ser con frecuencia incumplido, como así lo demuestra que en el siglo XIV el obispo don Juan ordena a los racioneros del coro, junto a otros beneficiados del cabildo, que no puedan abandonar el coro una vez que estén presentes en él, se les prohibe hablar a unos con otros y deben además presentarse con su hábito. Un año después de esta constitución, en 1421, al no cumplirse lo reglamentado, se debe insistir de nuevo en la imposición de una multa y del impago de la ración durante un mes o el encierro en la torre del obispo un día en caso de incumplimiento de lo anteriormente establecido.

El hospital contaba además con un proveedor, del que poseemos la primera noticia en 1288 cuando Martín Pérez, canónigo de León y proveedor del hospital de San Marcelo vende a doña Marina, moradora en San Marcelo unas casas que posee en la judería, del cual no se nos especifica cuáles eran sus funciones, pero suponemos que se encargaba de suministrar al hospital todos aquellos bienes que necesitase (alimentos, ropa, útiles de cocina, etc).

Otro cargo presente en dicho hospital era el del hospitalero, del que comenzamos a tener noticias en 1317, cuando fray Bienvenido, que desempeñaba dicho cargo, firma en un documento como testigo ${ }^{34}$, que deducimos, aunque no se nos diga su cometido, que era la persona encarga del cuidado directo de los enfermos.

Además al buen funcionamiento del hospital contribuían otros servidores, entre los que se encuentran clérigos de la iglesia catedral, al mismo tiempo que personas que ejercían tareas de carácter doméstico. En 1305 el obispo Gonzalo reduce a ocho los once clérigos que estaban asignados a dicho hospital.

En época moderna, concretamente en 1531, el abad don Guillermo Desprats, de acuerdo con el obispo, renunció a la administración, pasando, además, el hospital a denominarse de San Antonio, y perdiendo su antiguo nombre, sin que halla datos relativos a los motivos que propiciaron este cambio ${ }^{35}$.

Durante el siglo XVII a este hospital se agregó el Hospital del Santo Sepulcro, o de don Gómez, y dos siglos más tarde, el dieciséis de

\footnotetext{
34 "Frey Bienvenido ospitalero del dicho lugar de Sant Marciel”. (ÁLVAREZ ÁLVAREZ, Y MARTÍN FUERTES, J.L., Archivo Histórico Municipal de León. Catálogo de los Documentos, León, 1982, $\mathrm{n}^{\circ}$ 72).

${ }^{35}$ VILLACORTA, T., El cabildo catedral de León. Estudio histórico- jurídico, siglos XII-XIX, León, 1974, p.443.
} 
enero de 1864, un incendio destruyó parcialmente el hospital, por lo que en la actualidad no disponemos de su estructura primitiva.

De manera regular el deán y el cabildo mandaban a varios de sus canónigos visitar la abadía de San Marcelo, lo que incluía el hospital dependiente de la misma. El objetivo de estas visitas periódicas era comprobar el buen funcionamiento interno de la abadía.

Este régimen de visitas no es exclusivo de ella, puesto que el cabildo supervisa de manera permanente todas sus propiedades y centros asistenciales dependientes de él, para garantizar que no se viera menguado su patrimonio, e incluso en aquellas instituciones hospitalarias no subordinadas al cabildo catedralicio, el caso más significativo en la ciudad leonesa es el del hospital de San Marcos, dependiente de la orden de Santiago, donde se realizan exámenes de manera regular con la misma finalidad.

Desgraciadamente no tenemos noticias de todas las inspecciones que se realizaron a dicha abadía, pero si tenemos constancia de algunas, fundamentalmente para los siglos bajomedievales, como la que es mandada en junio de 1461 por el deán y el cabildo a los canónigos de la catedral leonesa, Fernando González de Ordás y Pedro de Carvajal, gracias a la cual conoceremos las estancias de las que constaba el hospital y el número de camas de que disponía, con lo que podemos hacer un estudio aproximado de la capacidad que en el último cuarto del siglo XV tenía el centro, y de la que hablaremos más adelante.

El 23 de junio de 1507 se encargará a los canónigos Pedro de Villada y Francisco de Valderas para que "visiten el ospital de Sant Marçiel e le hagan proveer de las cosas neçesarias dieronles poder por ello ${ }^{36,}$.

\section{3- La alimentación.}

En lo que respecta a la alimentación que se procuraba a los enfermos alojados en dicho hospital sabemos que en 1305 el obispo Don Gonzalo y el cabildo disponen que el abad de San Marcelo debe dar al hospital en la época de la recolección del pan y del vino, cuatrocientos estopos de cereales, la mitad de trigo y la otra mitad de "sigilo", o trigo escogido, así como doce heminas de vino para los pobres, más trescientos maravedís, así como verduras, legumbres, manteca y aceite suficientes para mantener la cocina del hospital. Además se añade que se debían

\footnotetext{
${ }^{36}$ Actas Capitulares, caja n ${ }^{\circ} 391$, documento $\mathrm{n}^{\circ} 9841$.
} 
distribuir de la siguiente forma: seis estopos de lo antedicho cada año, media libra de aceite cada día de ayuno y media de manteca los que fuesen de carne, debiéndose entregar a dicho hospitalero toda la manteca en la fiesta de la natividad de la Virgen y el aceite en la domínica de la cuadragésima. En 1306 el propio prelado y el cabildo repiten lo ordenado en $1300^{37}$.

\section{4- El edificio: su distribución y emplazamiento.}

El hospital de San Marcelo se encontraba situado al oeste de la ciudad, entre la iglesia de tal advocación y la casa del ayuntamiento ${ }^{38}$, quedando la fachada frente a la plaza del mismo nombre, tal fachada era de corta dimensión, ya que sólo tenía cuarenta y un pies lineales.

Conocemos únicamente una descripción detallada de las estancias en que se distribuía el hospital ya muy avanzada la Edad Media y en época moderna, cuando el hospital había adoptado el nombre de Don Gómez; siendo las noticias de que disponemos para el período medieval mucho más difusas, pero aunque en la Edad Moderna el hospital se enriqueciese con alguna estancia nueva, la distribución sería básicamente la misma que la que el hospital poseía en los últimos siglos del medievo, por lo que la descripción exacta que tenemos sobre la disposición de las estancias del hospital en el período moderno puede servirnos de punto de referencia para la Edad Media.

La primera noticia que poseemos sobre mejoras realizadas en el hospital data de la época en que es canónigo don Gómez, quien mejoró notablemente el hospital creando dos alas para ambos sexos.

Gracias a las noticias de que disponemos de la visita a la abadía de San Marcelo de los canónigos González de Ordas y Pedro de Carvajal, sabemos de cuantas estancias constaba el hospital en 1461, que eran las siguientes en la planta baja:

- Sala de los pobres: de ella dicen que faltan algunas tablas y un aguilón que estaba sobre el techo de la sala, que está malo y es necesario "lo adobar".

\footnotetext{
${ }^{37}$ Peregrinaciones, t.I, p.333.

${ }^{38}$ De hecho desde al menos finales del siglo XIII el concejo se reunía en el portal del hospital de San Marcelo para la toma de decisiones, como ocurrirá, por ejemplo, en el acuerdo que realizan el concejo y el cabildo de la ciudad de León en 1286 sobre el portazgo "estando el conceyo de Leon aiuntado enno Portal del Espital de Sant Marciel do se suel aiuntar per pregon que ye se uso et costumbre de la ciutat". (Archivo de la Catedral de León, $\mathrm{n}^{\circ} 6205$ y ESTEPA, La ciudad de León, p.485).
} 
- Sala principal, con catorce camas, de ellas cuatro estaban en buen estado, y las restantes las "conviene aderezar".

- Sala segunda delante del altar de San Antón, con doce lechos, todos ellos hábiles para poder dormir en ellos los pobres. Se indica que la sala está bien reparada.

- Sala de mujeres, con ocho lechos, de los cuales sólo se puede dormir en seis, los dos restantes están "do adobar".

- Capilla. Está en buen estado y en ella se encuentran un códice de plata y una vestimenta.

En la planta alta había varias cámaras, situadas sobre el corral, con tres camas, las cuales estaban aptas para dormir. Parece ser que toda la planta alta se encontraba en un buen nivel de conservación.

En dichas cámaras se encuentran ochenta y cinco cabezales, viejos y rotos, quince almadraques viejos, cuatro cocedras de lana, once reposteros, nueve buenos y dos viejos, cuatro sobrelechos y veintidós mantas, cuatro buenas y el resto viejas y rotas.

El hospital disponía de una cocina que también es visitada, la encuentran en buenas condiciones con "unos fierros muy buenos y un caldero grande y una caldera rota".

Visitan el resto de las dependencias del hospital y las hallan en un estado aceptable, aunque en las conclusiones sobre su visita añaden que hace falta retejar.

Una vez analizado el resultado de la visita podemos concluir que a finales de la Edad Media el hospital de San Marcelo contaba con treinta y siete lechos, de los cuales sólo veinticinco eran aptos para dormir, mientras que los doce restantes estaban en tan mal estado que no se podía descansar en ellos.

El hospital de San Marcelo, examinado el número de camas de que disponía en esta fecha y del estado en que se encontraban sus estancias, podemos concluir que presentaba un estado razonable de conservación, aunque con necesidad de hacer algunas reparaciones básicas.

Donde encontramos un panorama más desolador es en el de los complementos de que constaba cada uno de los lechos (mantas, cocedras, almadraques), y que sería fruto de donaciones de particulares. 
Las causas de esta desidia podrían ser varias, en primer lugar todos los útiles podían haber sido desgastadas por el uso y también por el paso del tiempo, y al no producirse nuevas donaciones o al no ser repuestas por piezas nuevas el resultado sería al que se llegó en 1461, pero esto no nos debería llevar a la conclusión errónea de que el hospital no tenía los suficientes medios para reparar y reponer las dependencias y los bienes de que disponía, pues las rentas que obtenía de ellos vemos que eran sustanciosas, lo que nos lleva a deducir, como es frecuente en otros hospitales en los siglos bajomedievales, que las ganancias obtenidas con las propiedades de los hospitales son más utilizadas con fines lucrativos que con el objetivo de favorecer una buena asistencia a los pobres y peregrinos.

Ya en época moderna el hospital contará con las siguientes dependencias: un zaguán, una botica y una capilla, llamada de San Antonio Abad, todas ellas emplazadas en el piso bajo. En la planta principal se encuentran las habitaciones del mayordomo, los cuartos del vicario, y agonizante, además de otras estancias de menor importancia destinadas a albergar a la servidumbre. También había dos paneras, droguería, depósito de cadáveres, cocina, salas de cirujía que dan al jardín, enfermería de hombres y de mujeres, etc ${ }^{39}$.

Por su tamaño podemos situar este hospital dentro de los hospitales de tipo medio, de tamaño superior a los instalados en casas particulares, pero sin llegar a la categoría de los grandes hospitales que aparecen más tarde.

A caballo entre los siglos dieciséis y diecisiete se construirá una nueva iglesia de San Marcelo, iniciándose las obras en 1588, y finalizando cuarenta años más tarde, en 1628. La maestría y la dirección de la obra se habían otorgado el quince de mayo de 1588, por parte del cabildo y del ayuntamiento leonés, a Juan de Rivero y Baltasar Gutiérrez ${ }^{40}$.

\footnotetext{
${ }^{39}$ Sobre el hospital de San Antonio Abad existe una interesante memoria de licenciatura realizada por Jacinto Gutiérrez Campillo titulada El Hospital de San Antonio Abad de la Ciudad de León en el siglo XVIII, leída en la Universidad de Cantabria, en el curso 1990-1991. Si lo comparamos con otros centros hospitalarios leoneses, como es el caso del hospital de Nuestra Señora La Blanca de Puente Villarente, edificado por iniciativa particular en los primeros años del siglo XVI, encontramos que todos ellos compartían como elementos comunes una capilla, una cocina, una panera, un patio entorno al que se organizaban las dependencias de la casa, estancias reservadas para las personas encargadas del mantenimiento del hospital, dormitorios separados para hombres y mujeres que se hospedaban en ellos, un pozo para abastecerse de agua, caballerizas, horno y bodega. Todas estas estancias estaban distribuidas en varios pisos del recinto. (CAMPOS BARDONA, M ${ }^{\mathrm{a}}$ D., "El Hospital de Nuestra Señora La Blanca del Puente Villarente y la arquitectura asistencial en el siglo XVI en León”, en Tierras de León, no 79-80, junio-septiembre de 1990, pp. 55-82).

${ }^{40}$ RIVERA, Arquitectura, p.156.
} 
Una serie de problemas de financiación, en primer lugar, y de ocupación en otros trabajos, tanto de Ribero (que por los años noventa trabajaba como maestro mayor de la catedral de Salamanca), como de Gutiérrez, que traspasa a Felipe de la Cajica sus funciones, los enfrentamientos entre ambos (Ribero y Cajica), en segundo lugar; provocan un retaso en las obras, que llegan a paralizarse con la muerte de Ribero en 1600, para continuar después hasta su conclusión en $1628^{41}$.

Más de siglo y medio después, el nueve de febrero de 1784, Carlos III dará una provisión al corregidor de la ciudad de León para que proceda a la construcción del lugar común del hospital de San Antonio Abad, de acuerdo con el proyecto presentado por el arquitecto Ventura Rodríguez $^{42}$.

En el siglo XVII al hospital de San Marcelo se agregó el de don Gómez, antes del Santo Sepulcro, incendiándose el dieciséis de enero de 1864, aunque posteriormente fue en gran parte restaurado.

Todavía a comienzos del siglo XX tenemos constancia de la existencia del hospital, pues en 1903 se conserva en el archivo del ayuntamiento de León un expediente de alineación y urbanización de los terrenos en que se halla instalado el hospital de san Antonio Abad, a pesar de en el libro de las peregrinaciones a Santiago de Compostela, Lacarra, Uría Ríu señalan que "desapareció al ser totalmente derruido a finales del siglo XIX"43.

\section{Conclusiones.}

Hablar del hospital de San Marcelo significa también hablar de uno de los principales centros asistenciales de la capital leonesa, y el primero documentado en la ciudad, en 1084. Tras su inicial ubicación en pleno corazón de la urbe, en 1098, el obispo Pedro lo trasladará muy cerca de la Puerta Cauriense, lugar donde habían estado implantadas las iglesias de Santiago, San Marcelo y San Adrián, lugar no tan céntrico como el anterior, pero igualmente punto de referencia importante para los pobres y peregrinos.

Este hospital, que por su capacidad se podría encuadrar en los de tipo intermedio, se enmarcará dentro del abundante número de fundacio-

\footnotetext{
${ }^{41}$ RIVERA, Arquitectura, pp.150-156.

${ }^{42}$ ÁLVAREZ ÁLVAREZ, C., y MARTín FUERTES, J.A., Archivo Histórico Municipal de León. Catálogo de los Documentos, León, 1982, León, $\mathrm{n}^{\circ} 1320$.

${ }^{43}$ Peregrinaciones, t.II, p.156.
} 
nes que, bien directa, o indirectamente se crean durante el reinado de Alfonso VI, no sólo dentro del marco urbano, sino también en otras villas del reino, entre las que la más significativa será la de Sahagún.

A lo largo de su historia sufrirá numerosos avatares, ya en 1306 pasó de ser beneficio perpetuo a administración temporal dependientes de la catedral, y de ser el primer hospital asentado en la ciudad, enriquecido con numerosas donaciones y cobro de impuestos, como el portazgo y el zavazogazgo, pasará en la Baja Edad Media a un clima de decadencia y corrupción, que se inserta dentro de una dinámica de declive de todos los centros hospitalarios de la ciudad, marcados por el propio clima político y económico de la corona, y que repercutirá en la calidad de la atención hacia los enfermos y peregrinos.

Junto con los hospitales de don Gómez, y el de San Antonio, serán los centros hospitalarios dependientes del cabildo catedralicio en la capital leonesa. En 1531 se fusionaron los hospitales de San Marcelo y el de San Antonio, adquiriendo el nuevo hospital el nombre de San Antonio, siendo este último, junto con el de don Gómez cedidos por el cabildo, en 1578, al ayuntamiento de la ciudad, a los que se agregaron, ese mismo año, las rentas del hospital de leprosos de San Lázaro.

Contaba para su administración con un abad, cuatro racioneros, un proveedor y un hospitalero, todos ellos bajo la supervisión directa del cabildo catedralicio que mandaba para vigilar su gestión a unos visitadores, que eran miembros del cabildo, pero a pesar de este control no se pudieron evitar los abusos, y así, en los siglos XIV, y principalmente el $\mathrm{XV}$, pasó a padecer un proceso de decadencia motivado por la compra e intercambio de los ofícios encargados de regir el centro, y las disputas internas por el control de la abadía, entre los abades con los racioneros, todos ellos más preocupados del lucro personal que de una buena gestión de la abadía. 


\section{Nombres de los abades y otros cargos documentados del Hospital de} San Marcelo.

\begin{tabular}{|c|c|c|}
\hline $\begin{array}{l}\text { Artículo I. } \\
\text { ño }\end{array}$ & Tipo de cargos & Documento \\
\hline 1143 & Martino & $C D C L, \mathrm{n}^{\circ} 1438$. \\
\hline 1195 & $\begin{array}{l}\text { Martín Micahelis, deán de la } \\
\text { iglesia de Santa María, y minis- } \\
\text { tro del hospital de San Marcelo. }\end{array}$ & $C D C L, \mathrm{n}^{\circ} 1719$. \\
\hline 1253 & $\begin{array}{l}\text { El anterior rector debió ser } \\
\text { Pedro Iohannis, tesorero, y tras } \\
\text { su muerte, el cabildo propondrá } \\
\text { como rector del hospital al ca- } \\
\text { nónigo Alfonso Martínez, quien } \\
\text { tenía de manera temporal la } \\
\text { dirección del hospital. }\end{array}$ & $C D C L, \mathrm{n}^{\circ} 2123$. \\
\hline 1261 & $\begin{array}{l}\text { Alfonso Martínez, abad de San } \\
\text { Marcelo. }\end{array}$ & $C D C L, \mathrm{n}^{\circ} 2226$. \\
\hline 1271 & $\begin{array}{l}\text { Martín Pelaz, clérigo de San } \\
\text { Marcelo. }\end{array}$ & $C D C L, \mathrm{n}^{\circ} 2311$. \\
\hline 1273 & $\begin{array}{l}\text { Pedro Iohannis, arcediano y } \\
\text { rector del hospital de San Mar- } \\
\text { celo. }\end{array}$ & $C D C L, \mathrm{n}^{\circ} 2332$. \\
\hline $1275-1288$ & $\begin{array}{l}\text { Martín Pérez, provisor del hos- } \\
\text { pital de San Marcelo, mayor- } \\
\text { domo y canónigo. }\end{array}$ & $\begin{array}{l}C D C L, \mathrm{n}^{\mathrm{o}} 2356,2365,2675, \\
2676, C A H D L, \text { Bachilleres, } \mathrm{n}^{\mathrm{o}} \\
32 .\end{array}$ \\
\hline 1296 & Ferandus Iohannis. & $\begin{array}{l}\text { Obituarios Medievales, pp. 342- } \\
343 .\end{array}$ \\
\hline 1305 & Pedro Rodríguez. & $C D C L, \mathrm{n}^{\circ} 2764$ \\
\hline 1308 & Pedro Rodríguez. & $C D C L, \mathrm{n}^{\circ} 2792$ y 2793. \\
\hline 1317 & $\begin{array}{l}\text { Frey Bienvenido, hospitalero de } \\
\text { San Marcelo. }\end{array}$ & $C D A M, \mathrm{n}^{\circ} 80$ \\
\hline 1320 & $\begin{array}{l}\text { Fernando Martini, abad de San } \\
\text { Marcelo. }\end{array}$ & CDSIL, doc. $\mathrm{n}^{\circ} 52$. \\
\hline 1331 & Fernandus Martini. & Obituarios Medievales, pp. $324^{44}$. \\
\hline $1346-1356$ & $\begin{array}{l}\text { Fernando Iohánez, abad de San } \\
\text { Marcelo. }\end{array}$ & $\begin{array}{l}C D S I L, \text { doc } \mathrm{n}^{\circ} 145, \text { y } C A H D, \mathrm{n}^{\circ} \\
60 \text {, t.I. }\end{array}$ \\
\hline 1362 & $\begin{array}{l}\text { Pedro Fernández, racionero de } \\
\text { San Marcelo. }\end{array}$ & $C A H D, \mathrm{n}^{\circ} 62, \mathrm{t} . \mathrm{I}$. \\
\hline $1376-1396$ & García Rodríguez, abad de San & $C D A C$, doc. $\mathrm{n}^{\circ} 77,93,126,177$, \\
\hline
\end{tabular}

\footnotetext{
${ }^{44}$ Sabemos por esta noticia que Fernandus Martini murió el treinta y uno de enero de 1331, dejando al cabildo catedralicio para que celebren su aniversario cuatrocientos maravedís.
} 


\begin{tabular}{|c|c|c|}
\hline & Marcelo. & 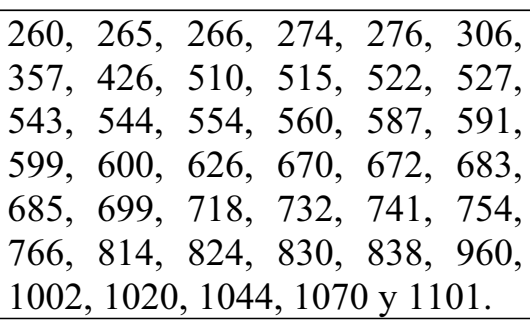 \\
\hline 1397 & García Rodríguez. & $\begin{array}{l}C D A C, \text { doc. } \mathrm{n}^{\circ} 1158,1168,1200 \text {, } \\
1213,1214 .\end{array}$ \\
\hline 1397 & $\begin{array}{l}\text { Juan Vinianes, rector de la igle- } \\
\text { sia de San Marcelo. }\end{array}$ & $C D A C$, doc. $\mathrm{n}^{\circ} 1199$. \\
\hline 1398 & García Rodríguez. & $\begin{array}{l}C D A C, \text { doc. } \mathrm{n}^{\mathrm{o}} 1238,1249,1250 \text {, } \\
1274 .\end{array}$ \\
\hline 1399 & orcía Podrígrez & $C D A C$, doc. $\mathrm{n}^{\mathrm{o}} 1326$. \\
\hline 1418 & Alfo & $\begin{array}{l}\text { Actas Capitulares, caja } \mathrm{n}^{\mathrm{o}} 383 \text {, } \\
\text { documento } \mathrm{n}^{\circ} 9797 \text { y } C D A C \text {, doc } \\
\mathrm{n}^{\circ} 920 \text {. }\end{array}$ \\
\hline $141 \mathrm{~s}$ & $\begin{array}{l}\text { Iohan Bondreville, abad de San } \\
\text { Marcelo. }\end{array}$ & $\begin{array}{l}\text { Extracto de Actas Capitulares, } \mathrm{n}^{\circ} \\
20,1956, \text { pp. } 129-130 \text { y } 174-175, \\
\text { Actas Capitulares, caja } \mathrm{n}^{\circ} 383 \text {, } \\
\text { documento } \mathrm{n}^{\circ} 9800 \text {. }\end{array}$ \\
\hline 1441. & $\begin{array}{l}\text { Alfonso Çeron, racionero de } \\
\text { San Marciel. }\end{array}$ & $\begin{array}{l}\text { Actas Capitulares, caja } \mathrm{n}^{\circ} 384 \text {, } \\
\text { documento } \mathrm{n}^{\circ} 9802 \text {. }\end{array}$ \\
\hline 1442. & $\begin{array}{l}\text { Sancho Fernández, abad de San } \\
\text { Marcelo. }\end{array}$ & $\begin{array}{l}\text { Actas Capitulares, caja } \mathrm{n}^{\circ} 384 \text {, } \\
\text { documento } \mathrm{n}^{\circ} 9802 .\end{array}$ \\
\hline 1448. & $\begin{array}{l}\text { Lope de Prado, racionero de } \\
\text { San Marciel. }\end{array}$ & $\begin{array}{l}\text { Actas Capitulares, caja } \mathrm{n}^{\circ} 384 \text {, } \\
\text { documento } \mathrm{n}^{\circ} 9803 \text {. }\end{array}$ \\
\hline 1448. & $\begin{array}{l}\text { Pedro Alonso, bachiller racio- } \\
\text { nero de San Marcelo. }\end{array}$ & $\begin{array}{l}\text { Actas Capitulares, caja } \mathrm{n}^{\circ} 384 \text {, } \\
\text { documento } \mathrm{n}^{\circ} 9803 \text {. }\end{array}$ \\
\hline 1452. & $\begin{array}{l}\text { Juan Estévanes, racionero de } \\
\text { San Marciel. }\end{array}$ & $\begin{array}{l}\text { Actas Capitulares, caja } \mathrm{n}^{\circ} 384 \text {, } \\
\text { documento } \mathrm{n}^{\circ} 9804 \text {. }\end{array}$ \\
\hline $1459-1460$ & $\begin{array}{l}\text { Gómez Barreguín, licenciado } \\
\text { en decretos, abad de San Mar- } \\
\text { celo y canónigo en la iglesia de } \\
\text { León. }\end{array}$ & $\begin{array}{l}\text { Actas Capitulares, caja } \mathrm{n}^{\mathrm{o}} 384 \text {, } \\
\text { documento } \mathrm{n}^{\circ} 9806 \text {. }\end{array}$ \\
\hline 1462. & $\begin{array}{l}\text { El arcediano de Valdemeriel, } \\
\text { Juan Martínez de Raga, y Pedro } \\
\text { Sánchez de Otheo, visitadores. }\end{array}$ & $\begin{array}{l}\text { Actas Capitulares, caja } \mathrm{n}^{\circ} 385 \text {, } \\
\text { documento } \mathrm{n}^{\circ} 9810 .\end{array}$ \\
\hline 1463 & $\begin{array}{l}\text { Francisco de Villalpando, arce- } \\
\text { diano de Mayorga, y Fernando }\end{array}$ & $\begin{array}{l}\text { Actas Capitulares, caja } \mathrm{n}^{\circ} 385 \text {, } \\
\text { documento } \mathrm{n}^{\circ} 9811 \text {. }\end{array}$ \\
\hline
\end{tabular}

\footnotetext{
${ }^{45}$ Alfonso González es abad de San Marcelo hasta el veintitrés de septiembre de 1419, día en el que muere, pasando a desempeñar el cargo Johan de Bondreville, colector del papa en Santiago de Compostela.
} 


\begin{tabular}{|c|c|c|}
\hline & & \\
\hline 1466 & $\begin{array}{l}\text { Pedro de Remondo y Lope de } \\
\text { Prado, racioneros de San Mar- } \\
\text { ciel. }\end{array}$ & $\begin{array}{l}\text { Actas Capitulares, caja } \mathrm{n}^{\circ} 385 \text {, } \\
\text { documento } \mathrm{n}^{\circ} 9813 \text {. }\end{array}$ \\
\hline 1466-1468. & $\begin{array}{l}\text { Rodrigo de la Rua, racionero de } \\
\text { San Marcelo. }\end{array}$ & $\begin{array}{l}\text { Actas Capitulares, caja } \mathrm{n}^{\circ} 385 \text {, } \\
\text { documento } \mathrm{n}^{\circ} 9813 \text { y } 9815 .\end{array}$ \\
\hline 1468 & $\begin{array}{l}\text { Pedro de Remondo, racionero } \\
\text { de San Marcelo. }\end{array}$ & $\begin{array}{l}\text { Actas Capitulares, caja } \mathrm{n}^{\mathrm{o}} 385 \text {, } \\
\text { documento } \mathrm{n}^{\circ} 9815 \text {. }\end{array}$ \\
\hline 1468 & $\begin{array}{l}\text { Gómez Díaz de Isla, arcediano } \\
\text { de Carvalleda, y abad de San } \\
\text { Marcelo. }\end{array}$ & $\begin{array}{l}\text { Actas Capitulares, caja } \mathrm{n}^{\circ} 385, \\
\text { documento } \mathrm{n}^{\circ} 9815^{46} \text {, caja } \mathrm{n}^{\circ} \\
386 \text {, documento } \mathrm{n}^{\circ} 9816 \text {. }\end{array}$ \\
\hline 1470 & $\begin{array}{l}\text { Vázquez de Mella, abad } \\
\text { Iarcelo. }\end{array}$ & $\begin{array}{l}\text { Actas Capitulares, caja } \mathrm{n}^{\circ} 386 \text {, } \\
\text { documento } \mathrm{n}^{\circ} 9816 \text {. }\end{array}$ \\
\hline 1470 & rigo racio- & $\begin{array}{l}\text { Actas Capitulares, caja } \mathrm{n}^{\mathrm{o}} 386 \text {, } \\
\text { documento } \mathrm{n}^{\circ} 9816 .\end{array}$ \\
\hline 1470 & $\begin{array}{l}\text { García de Mansilla, abad de } \\
\text { San Marcelo. }\end{array}$ & $\begin{array}{l}\text { Actas Capitulares, caja } \mathrm{n}^{\circ} 386 \text {, } \\
\text { documento } \mathrm{n}^{\circ} 9816 \text {. }\end{array}$ \\
\hline 1470 & $\begin{array}{l}\text { de la Rua, clérigo ra- } \\
\text { de San Marcelo. }\end{array}$ & $\begin{array}{l}\text { Actas Capitulares, caja } \mathrm{n}^{\mathrm{o}} 386 \text {, } \\
\text { documento } \mathrm{n}^{\circ} 9816 .\end{array}$ \\
\hline 1474 & rigo racione- & $\begin{array}{l}\text { Actas Capitulares, caja } \mathrm{n}^{\circ} 386 \text {, } \\
\text { documento } \mathrm{n}^{\circ} 9817 \text {. }\end{array}$ \\
\hline 1476- & Antonio de Villagómez, abad ${ }^{47}$. & $\begin{array}{l}\text { Actas Capitulares, caja } \mathrm{n}^{\circ} 386 \text {, } \\
\text { documento } \mathrm{n}^{\circ} 9818 \text {. }\end{array}$ \\
\hline 1479 & Góm & $\begin{array}{l}\text { Extracto de Actas Capitulares, } \mathrm{n}^{\circ} \\
31,1962, \text { p. } 142 .\end{array}$ \\
\hline $1480-1481$ & Fran & $\begin{array}{l}\text { Extracto de Actas Capitulares, } \mathrm{n}^{\circ} \\
31 \text { y } 32,1962, \text { pp. } 143 \text { y } 313 .\end{array}$ \\
\hline 1482 & $\begin{array}{l}\text { Gómez de Isla, abad de San } \\
\text { Marcelo. }\end{array}$ & $\begin{array}{l}\text { Actas Capitulares, caja } \mathrm{n}^{\circ} 387 \text {, } \\
\text { documento } \mathrm{n}^{\circ} 9822 .\end{array}$ \\
\hline 1482 & $\begin{array}{l}\text { Francisco de Villamizar, abad } \\
\text { de San Marcelo. }\end{array}$ & $\begin{array}{l}\text { Actas Capitulares, caja } \mathrm{n}^{\circ} 388 \text {, } \\
\text { documento } \mathrm{n}^{\circ} 9823 \text {. }\end{array}$ \\
\hline 1482 & Francisco de Villamizar, abad & Actas Capitulares, caja $\mathrm{n}^{\circ} 388$, \\
\hline
\end{tabular}

\footnotetext{
${ }^{46}$ Este día tomó posesión del cargo, obtenido en truque por el puesto de maestrescuela de Zamora.

${ }^{47}$ En 1478 encontramos (aunque ya diez años antes existían problemas entre ambos, figurando los dos en la documentación como abades de San Marcelo hasta 1476, año en que ya aparece como abad sólo Antonio de Villagómez) a Gómez Díaz de Isla, abad que fue de San Marcelo, pleiteando con Antonio de Villagómez, que era abad en esos momentos y sobrino del chantre de la catedral. El pleito es llevado a Roma, y parece insertarse dentro del proceso de concesión de prebendas y cargos a familiares y amigos de miembros de los cabildos catedralicios, como es en este caso, o, como ocurrirá en otros casos a beneficiados papales, sucesos muy frecuentes durante toda la Edad Media.

${ }^{48}$ Ese mismo día se reintegra la abadía de San Marcelo a don Gómez Díaz de Isla que ocupará de nuevo el cargo hasta el once de septiembre de 1480 cuando toma posesión de la abadía Francisco de Villamizar, probablemente por defunción del primero.
} 


\begin{tabular}{|c|c|c|}
\hline & de San Marcelo. & documento $\mathrm{n}^{\circ} 9823$. \\
\hline 1482 & $\begin{array}{l}\text { Francisco de Villamizar, abad. } \\
\text { Francisco de Moros, racionero. }\end{array}$ & $\begin{array}{l}\text { Actas Capitulares, caja } \mathrm{n}^{\mathrm{o}} 388 \text {, } \\
\text { documento } \mathrm{n}^{\circ} 9823 \text {. }\end{array}$ \\
\hline $1482^{49}$ & Francisco de Villamizar, abad. & $\begin{array}{l}\text { Actas Capitulares, caja } \mathrm{n}^{\mathrm{o}} 388 \text {, } \\
\text { documento } \mathrm{n}^{\circ} 9823 \text {. }\end{array}$ \\
\hline 1486. & $\begin{array}{l}\text { Pedro de Ávila, provisor, Antón } \\
\text { Bardín, Pedro de Arbaes, canó- } \\
\text { nigo, visitadores de la abadía de } \\
\text { San Marcelo. } \\
\end{array}$ & $\begin{array}{l}\text { Actas Capitulares, caja } \mathrm{n}^{\circ} 388, \\
\text { documento } \mathrm{n}^{\circ} 9825 .\end{array}$ \\
\hline 1486 & $\begin{array}{l}\text { Pedro de Villada, doctor en } \\
\text { decretos y abad de San Marce- } \\
\text { lo. }\end{array}$ & $\begin{array}{l}\text { Actas Capitulares, caja } \mathrm{n}^{\circ} 388 \text {, } \\
\text { documento } \mathrm{n}^{\circ} 9825 .\end{array}$ \\
\hline 1487 & $\begin{array}{l}\text { Luis González de Oviedo, } \\
\text { maestrescuela, Fernando de } \\
\text { Salazar, beneficiado de la igle- } \\
\text { sia, visitadores del hospital de } \\
\text { San Marcelo. }\end{array}$ & $\begin{array}{l}\text { Actas Capitulares, caja } \mathrm{n}^{\circ} 388 \text {, } \\
\text { documento } \mathrm{n}^{\circ} 9825 \text {. }\end{array}$ \\
\hline 1487 & $\begin{array}{l}\text { é de Oviedo, clérigo } \\
\text { de San Marcelo. }\end{array}$ & $\begin{array}{l}\text { Actas Capitulares, caja } \mathrm{n}^{\circ} 388, \\
\text { documento } \mathrm{n}^{\circ} 9826 .\end{array}$ \\
\hline 1488 & Mar- & $\begin{array}{l}\text { Actas Capitulares, caja } \mathrm{n}^{\circ} 388, \\
\text { documento } \mathrm{n}^{\circ} 9826 .\end{array}$ \\
\hline $1488-1503$ & Pedro García de Vill & $\begin{array}{l}\text { Actas Capitulares, caja } \mathrm{n}^{\circ} 388, \\
\text { documentos } \mathrm{n}^{\circ} 9826,9827 ; \text { caja } \\
\mathrm{n}^{\mathrm{o}} 389, \text { documentos } \mathrm{n}^{\mathrm{o}} 9831, \\
9832,9833 ; \text { caja } \mathrm{n}^{\circ} 390, \text { docu- } \\
\text { mentos } \mathrm{n}^{\circ} 9834,9836,9837, \\
\text { 9838, y CDCL } \mathrm{n}^{\circ} 4366 .\end{array}$ \\
\hline 1491 & Ortiz, racionero de San & $\begin{array}{l}\text { Actas Capitulares, caja } \mathrm{n}^{\mathrm{o}} 389, \\
\text { documento } \mathrm{n}^{\circ} 9828 .\end{array}$ \\
\hline 1497 & $\begin{array}{l}\text { Bartolomé González, clérigo } \\
\text { racionero de San Marcelo. }\end{array}$ & $\begin{array}{l}\text { Actas Capitulares, caja } \mathrm{n}^{\mathrm{o}} 389, \\
\text { documento } \mathrm{n}^{\circ} 9832 \text {. }\end{array}$ \\
\hline 1503 & $\begin{array}{l}\text { El licenciado de San Pedro y } \\
\text { Gil de Medina, visitadores del } \\
\text { hospital de San Marciel }\end{array}$ & $\begin{array}{l}\text { Actas Capitulares, caja } \mathrm{n}^{\mathbf{0}} 390 \text {, } \\
\text { documento } \mathrm{n}^{\circ} 9838 \text {. }\end{array}$ \\
\hline $1504^{50}$ & $\begin{array}{l}\text { Jorge de Gordón, canónigo y } \\
\text { abad de San Marciel }\end{array}$ & $\begin{array}{l}\text { Actas Capitulares, caja } \mathrm{n}^{\mathrm{o}} 390, \\
\text { documento } \mathrm{n}^{\circ} 9838\end{array}$ \\
\hline 1506 & $\begin{array}{l}\text { Alonso Castaño, abad de San } \\
\text { Marciel. }\end{array}$ & $\begin{array}{l}\text { Actas Capitulares, caja } \mathrm{n}^{\mathrm{o}} 390, \\
\text { documento } \mathrm{n}^{\circ} 9839 .\end{array}$ \\
\hline 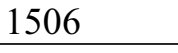 & Gillermo Desprats, abad de San & Actas Capitulares, caja $\mathrm{n}^{\circ} 390$ \\
\hline
\end{tabular}

\footnotetext{
${ }^{49}$ Este día, por carta papal, Gómez Díaz de Isla es restituido de nuevo en la abadía.

${ }^{50}$ Ese día es nombrado como abad, aunque el quince de enero de 1504 el anterior abad, Pedro de Villada, ya había muerto.
} 


\begin{tabular}{|c|c|c|}
\hline & Marciel. & documento $^{\circ} 9839$ \\
\hline 1506 & $\begin{array}{l}\text { Betanços y Villada, visitadores } \\
\text { del hospital de San Marciel }\end{array}$ & $\begin{array}{l}\text { Actas Capitulares, caja } \mathrm{n}^{\circ} 390, \\
\text { documento } \mathrm{n}^{\circ} 9839 .\end{array}$ \\
\hline 1507 & $\begin{array}{l}\text { Francisco de Valderas y Pedro } \\
\text { de Villada, canónigos y visita- } \\
\text { dores del hospital de San Mar- } \\
\text { ciel }\end{array}$ & $\begin{array}{l}\text { Actas Capitulares, caja } \mathrm{n}^{\circ} 391 \text {, } \\
\text { documento } \mathrm{n}^{\circ} 9840 .\end{array}$ \\
\hline 1511 & $\begin{array}{l}\text { Pedro de Villada y Juan de } \\
\text { Villafañe, canónigos y visitado- } \\
\text { res del hospital de San Marcelo. }\end{array}$ & $\begin{array}{l}\text { Actas Capitulares, caja } \mathrm{n}^{\circ} 391 \text {, } \\
\text { documento } \mathrm{n}^{\circ} 9842 \text {. }\end{array}$ \\
\hline 1512 & $\begin{array}{l}\text { Bartolomé de Valderas, y Be- } \\
\text { tanços, visitadores. }\end{array}$ & $\begin{array}{l}\text { Actas Capitulares, caja } \mathrm{n}^{\circ} 391 \text {, } \\
\text { documento } \mathrm{n}^{\circ} 9843 \text {. }\end{array}$ \\
\hline 1514 & $\begin{array}{l}\text { Juan Vázquez, prior y Alonso } \\
\text { Gutiérrez de Sahagún, visitado- } \\
\text { res del Hospital de San Marciel. }\end{array}$ & $\begin{array}{l}\text { Actas Capitulares, caja } \mathrm{n}^{\mathrm{o}} 391, \\
\text { documento } \mathrm{n}^{\circ} 9843 .\end{array}$ \\
\hline
\end{tabular}

